\title{
Phenological responses of Pseudomallada (Neuroptera: Chrysopidae): Comparative data from three Nearctic species and interspecific hybrids
}

\author{
MAurice J. TAUBER* and CATHERINe A. TAUBER \\ Department of Entomology, Cornell University, Ithaca, NY 14853-2601, USA, and Department of Entomology and Nematology, \\ University of California, Davis, CA 95616, USA; e-mail: cat6@cornell.edu
}

Key words. Neuroptera, Chrysopidae, Pseudomallada spp., larval diapause, photoperiod, temperature and development, quantitative response to daylength

\begin{abstract}
Three Nearctic species - Pseudomallada macleodi (Adams \& Garland), P. perfectus (Banks), and P. sierra (Banks) - share a suite of phenological characteristics with their Western Palearctic congeners. They overwinter as free-living larvae (primarily third instars) in a photoperiodically induced diapause. For these three species, the critical photoperiods for diapause induction fell between LD 16:8 and LD 14:10. In the laboratory, larvae remained responsive to daylength throughout diapause - short daylengths maintained diapause until diapause terminated spontaneously or death occurred. Transfer of diapausing larvae from short to intermediate or longer days accelerated diapause development, apparently in a quantitative response to daylength. A period of chilling appeared to delay, rather than hasten, diapause development. In general, the expression of diapause in F1 hybrids (P. perfectus $\times$ P. sierra) resembled that of the parents; there were minor differences in some features. Among populations of the three species under non-diapause conditions, the times for complete development (egg hatch to adult emergence) ranged between 40 and 50 days $\left(23.9^{\circ} \mathrm{C}\right)$. Under long-day conditions, developmental rates of the P. perfectus egg and prepupal-pupal stages were linearly related to temperature; we provide thermal thresholds and heat-degree days for these stages. In contrast, developmental rates of free-living larvae did not have a linear relationship with temperature; photoperiod may interact with temperature to affect non-diapause development in these stages.
\end{abstract}

\section{INTRODUCTION}

The green lacewing genus Pseudomallada (previously named Chrysopa, Anisochrysa, Mallada, Navasius, Dichochrysa) is widely distributed throughout the Old World, with centers of diversity in the Mediterranean Basin, Africa, and Asia (Brooks \& Barnard, 1990; Tsukaguchi, 1995; Brooks, 1997; Aspöck et al., 2001; Dong et al., 2004; Oswald, 2013). Only five of its $\sim 165$ species are reported from the New World (Adams, 1978; Adams \& Garland, 1982), and these five species are restricted to North America; none are known from Central or South America.

Pseudomallada is considered among the important groups of predaceous species for use in biological control of agricultural pests (Tsukaguchi, 1995; Daane, 2001; Pappas et al., 2011; Pantaleoni, 2014); nevertheless the phenology of very few of its species has been investigated. For example, the overwintering stage is reported for only eight species - seven from the Western Palearctic (Withycombe, 1922; Principi \& Castellari, 1970; Séméria, 1977; Principi \& Sgobba, 1993; Canard et al., 1992; Volkovich, 1998) and one from the Nearctic (Smith, 1922). Several other species were reared in the laboratory, but their hibernating stages were not reported (Tsukaguchi, 1995; Haruyama et al., 2012), and no phenological data exist for the African or Asian species. Experimental data on photoperiodic and other responses that underlie seasonal cycles exist for five Palearctic species (e.g., Principi \& Sgobba, 1987, 1993; Canard \& Grimal, 1993; Volkovich, 1998; Pappas
\& Koveos, 2011; see Discussion, below), but comparable information is unavailable from other regions of the world.

During a twelve-year period, we took advantage of fortuitous opportunities to accumulate experimental data on the phenological (photoperiodic and thermal) responses from three of North America's five Pseudomallada species. Herein, to broaden the geographic base of comparative information on the phenology of the genus, we present these data within the context of information from Palearctic species. Furthermore, we hope to stimulate additional studies that explore the seasonal adaptations and photoperiodic responses of Pseudomallada species throughout the broad range of the genus.

\section{MATERIAL AND METHODS}

\section{Sites, stocks and rearing}

We examined populations of three Pseudomallada species from widely separated localities in the United States (see Table 1). These species occur in midwestern and western parts of the country, at a considerable distance from our laboratory at Cornell University. Consequently, our studies relied on living specimens that colleagues sent to us (or that we collected on brief field trips focused on other research). Also, because our source material was scarce and unpredictable in the timing of arrival at our laboratory, not all populations of each species were subjected to each of the treatments and/or experiments. Our choices in experimental design were based on the availability of resources at the time the specimens were collected or sent to us.

One to several field-collected females from each population formed the parental sources for most of our experiments; un-

\footnotetext{
* Deceased October 6, 2014.
} 
TABLE 1. Source of parental stock for experiments with North American Pseudomallada species.

\begin{tabular}{|c|c|c|}
\hline $\begin{array}{l}\text { Locality } \\
\text { (Collector) }\end{array}$ & $\begin{array}{l}\text { Date (stage collected) } \\
\text { (Tauber Lot Number) }\end{array}$ & Experiments (generation ${ }^{1}$ ) \\
\hline \multicolumn{3}{|l|}{ Pseudomallada macleodi } \\
\hline $\begin{array}{l}\text { Stephenville population } \\
\text { Texas: Erath Co., Stephenville } \\
\text { (C.W. Agnew) }\end{array}$ & $\begin{array}{l}\text { 11-V-1982 (eggs \& adults) } \\
\quad(82: 001) \text { blacklight }\end{array}$ & Diapause induction (F1) \\
\hline $\begin{array}{l}\text { Manhattan population } \\
\text { Kansas: Riley Co., Ashland Bottoms, nr. Manhattan } \\
\text { (J.R. Nechols, R.G. Helgesen, M.J. \& C.A. Tauber) }\end{array}$ & $\begin{array}{c}\text { 28-V-1986 (eggs, larvae \& adults) } \\
\text { (86:002) hackberry, mulberry, burr oak }\end{array}$ & Diapause induction (F1) \\
\hline \multicolumn{3}{|l|}{ Pseudomallada perfectus } \\
\hline $\begin{array}{l}\text { Huachuca Mts population } \\
\text { Arizona: Cochise Co., Miller Cyn, Huachuca Mts, 5,500' } \\
\text { (J.A. Powell) }\end{array}$ & $\begin{array}{l}\text { 9-VIII-1974 (adults) } \\
\text { (74:052) at light }\end{array}$ & $\begin{array}{l}\text { Diapause induction (F1) } \\
\text { Diapause termination (F2) }\end{array}$ \\
\hline $\begin{array}{l}\text { Shasta Lake population } \\
\text { California: Shasta Co., Moore Crk, Shasta Lake, } \\
\text { McCloud Branch, } 8 \text { airmiles NW O’Brien } \\
\text { (J.A. Powell) }\end{array}$ & $\begin{array}{l}\text { 26-VIII-1975 (adults) } \\
\text { (75:040) blacklight }\end{array}$ & Diapause induction (F1) \\
\hline $\begin{array}{l}\text { Redding population } \\
\text { California: Shasta Co., Redding } \\
\text { (R.B. Miller) }\end{array}$ & $\begin{array}{l}\text { 10-VIII-1981 } \\
\text { (eggs, larvae, \& adults) } \\
(81: 020)\end{array}$ & $\begin{array}{l}\text { Diapause induction (F1) } \\
\text { Diapause termination (F1) } \\
\text { Cross with } P \text {. sierra (F1) } \\
\text { Diapause induction (F2) } \\
\text { Diapause termination (F2) }\end{array}$ \\
\hline $\begin{array}{l}\text { Kings Canyon population } \\
\text { California: Fresno Co., Ten Mile Crk, Kings Cyn Natl } \\
\text { Forest, } \sim 3 \text { mi. NE Hume } \\
\text { (C.A. \& A.J. Tauber) }\end{array}$ & $\begin{array}{l}11-\text { VIII-1983 } \\
\text { (eggs, larvae \& adults) } \\
(83: 004) \text { black oak }\end{array}$ & $\begin{array}{l}\text { Diapause induction (F1) } \\
\text { Temperature-development (F2) }\end{array}$ \\
\hline
\end{tabular}

\title{
Pseudomallada sierra
}

Redding population

California: Shasta Co., Redding 30-V-1981

(R.B. Miller) ～(eggs, larvae \& adults) (81:002)

\author{
Diapause induction (F1) \\ Cross with P. perfectus (F1) \\ Diapause induction (F2) \\ Diapause termination (F2)
}

$\overline{{ }^{1} \text { Generation: F1 - experiment with first generation offspring of field-collected female(s); F2 - experiment with second generation }}$ offspring of field-collected female(s).

less noted to the contrary, tests were conducted with their F1 offspring. Larvae were reared in individual vials on the eggs of Sitotroga cerealella (Olivier). Adults had continuous access to water and a mixture of protein hydrolysate of yeast, Wheast ${ }^{\circledR}$, honey, and sugar (1:1:1:1 ratio, by volume). Except where stated otherwise, rearing was done at $23.9 \pm 1{ }^{\circ} \mathrm{C}$. All other temperatures also were maintained within $\pm 1^{\circ} \mathrm{C}$; humidity was not controlled.

The species identities of all populations were confirmed through published keys and descriptions (primarily Adams \& Garland, 1982). Voucher specimens are deposited in the Essig Museum of Entomology, University of California, Berkeley [EMEC Nos. 735499-735598, 1068000-1068129].

\section{Experiments}

\section{Diapause induction - photoperiod}

This experiment evaluated the influence of photoperiod on the induction and maintenance of diapause; it sought to determine: (a) the diapausing stage or stages, (b) the critical photoperiod for diapause induction, (c) the influence of photoperiod on the duration (or depth) of diapause, and (d) the photoperiodic responses of prediapause and postdiapause stages. Altogether, seven geographic populations from three species were tested: P. macleodi (Manhattan, KS and Stephenville, TX populations); P. perfectus (Huachuca Mts, AZ; Shasta Lake, CA; Redding, CA; and Kings
Canyon, CA populations), and P. sierra (Redding, CA population) (see Tables 1, 2).

Eggs (one to three days old) from each population were distributed among constant photoperiods (generally LD 10:14, 12:12, $14: 10$, and $16: 8$; in two cases LD $13: 11$ ), all at $23.9^{\circ} \mathrm{C}$; the number of individuals in each treatment varied (see Table 3 ). Rearing conditions were as described above, and for each individual, we recorded larval molts (3 instars), cocoon spinning, adult emergence, and death; we did not distinguish between the prepupal and pupal stages within the cocoon. Also, for five populations (with at least one for each species) we recorded the egg incubation periods; in all populations, this period ranged between 5-7 days and was not affected by photoperiod. Thus the incubation period was not considered in the analysis of photoperiodic responses.

Occasionally, prepupal larvae went through cocoon-spinning motions, but no silk was produced. In many of these cases, the larva underwent metamorphosis to the pupal or pupal and adult stages without a cocoon. If the resulting pupa or adult appeared healthy (i.e. survived more than a day) we included the life stage data. A significantly prolonged third instar indicated a photoperiodic effect on development that we, and previous investigators (e.g., Principi et al., 1977; Canard et al., 1990; Principi \& Sgobba, 1993), consider to be diapause. 
TABLE 2. Developmental times (egg hatch to adult emergence) for three North American Pseudomallada species [Photoperiod: LD 16:8; Temperature: $23.9 \pm 1.0^{\circ} \mathrm{C}$ ]. Values followed by same letter are not significantly different (ANOVA, with Bonferroni test, $\mathrm{p}<0.05$ ).

\begin{tabular}{lccc}
\hline Species & Time [no. days, & Survival Sex Ratio \\
$\quad$ Locality & $\mathrm{x} \pm$ s.d., $\mathrm{n}]$ & {$[\%, \mathrm{n}]$} & {$[\mathrm{F}: \mathrm{M}]$} \\
\hline $\begin{array}{l}\text { P. } \text { macleodi } \\
\quad \text { Stephenville, Texas }\end{array}$ & $46.9 \pm 4.2(12) \mathrm{b} 100(12)$ & $2: 6$ \\
$\quad$ Manhattan, Kansas & $40.8 \pm 1.7(17) \mathrm{a} 100(18)$ & $7: 9$ \\
P. perfectus & & & \\
$\quad$ Redding, California & $42.1 \pm 1.5(25) \mathrm{a}$ & $86(29)$ & $11: 8$ \\
$\quad$ Kings Canyon, California & $49.9 \pm 3.9(30) \mathrm{c}$ & $91(35)$ & $15: 16$ \\
P. sierra & & & \\
$\quad$ Redding, California & $40.8 \pm 2.3(38) \mathrm{a}$ & $93(14)$ & $7: 6$ \\
\hline
\end{tabular}

2. Diapause termination - photoperiod, temperature

These experiments focused on the influence of photoperiodic increases and decreases, as well as low temperature ("chilling"), on the rate of diapause development leading to diapause termination and cocoon formation.

The first experiment dealt solely with photoperiod; in this test we transferred diapausing third instars that had been reared under various short-day regimens, to either longer or shorter daylengths; then, we recorded cocoon formation (i.e., an event signifying that larvae had terminated diapause and undergone postdiapause development leading to spinning) (Table 4). For comparison, we maintained a cohort of equivalent larvae under the original short-day condition. This test was conducted with $P$. perfectus - specifically 34-day-old, diapausing third-instar offspring of field-collected females from the Redding, CA popula-

TABLE 3. Photoperiodic influence on preimaginal development of three Pseudomallada species [Temperature: $23.9 \pm 1.0^{\circ} \mathrm{C} ; \mathrm{L} 1-\mathrm{L} 3$ $=$ instar number; cocoon $=$ prepupal third instar + pupa $]$. Within each population and within each column, values followed by same letter are not significantly different (ANOVA, with Bonferroni test, $\mathrm{p}<0.05$ ).

\begin{tabular}{|c|c|c|c|c|c|}
\hline \multirow{2}{*}{$\begin{array}{l}\text { Species } \\
\text { Locality } \\
\text { Photoperiod }\end{array}$} & \multicolumn{3}{|c|}{ Developmental time, Mean \pm SD, days $(\mathrm{n})$} & \multirow[b]{2}{*}{ Larval survival rate } & \multirow{2}{*}{$\begin{array}{l}\text { Time within cocoon } \\
\text { Mean } \pm \text { SD, days (n) }\end{array}$} \\
\hline & L1 & L2 & Free-living L3 & & \\
\hline \multicolumn{6}{|c|}{ Pseudomallada macleodi } \\
\hline LD $16: 8$ & $7.2 \pm 0.4(17) \mathrm{a}$ & $6.6 \pm 0.7(17) \mathrm{a}$ & $8.5 \pm 0.8(17) \mathrm{a}$ & $100 \%(17)$ & $18.4 \pm 0.8(17) \mathrm{a}$ \\
\hline LD $14: 10$ & $8.2 \pm 0.6(17) b$ & $22.5 \pm 7.7(17) \mathrm{b}$ & $77.3 \pm 40.8(14) b$ & $82.3 \%(17)$ & $20.0 \pm 16(12) b$ \\
\hline LD 12:12 & $7.3 \pm 0.4(16) \mathrm{a}$ & $8.1 \pm 0.6(16) \mathrm{a}$ & $108(1)$ & $6.3 \%(16)^{1}$ & $20(1)$ \\
\hline $\begin{array}{l}\text { LD 10:14 } \\
\text { Stephenville, Te }\end{array}$ & $7.0 \pm 0.4(19) \mathrm{a}$ & $7.5 \pm 0.8(19) \mathrm{a}$ & - & $0 \%(19)^{2}$ & - \\
\hline LD $16: 8$ & $9.3 \pm 0.7(16) \mathrm{a}$ & $6.8 \pm 0.4(14) \mathrm{a}$ & $14.8 \pm 2.0(12) \mathrm{a}$ & $95.0 \%(20)$ & $17.8 \pm 1.0(12)$ \\
\hline LD 10:14 & $10.2 \pm 0.7(13) b$ & $7.2 \pm 0.8(13) \mathrm{b}$ & $131.5 \pm 16.3(2) b$ & $15.3 \%(13)^{3}$ & - \\
\hline \multicolumn{6}{|c|}{ Pseudomallada perfectus } \\
\hline \multicolumn{6}{|c|}{ Huachuca Mts, Arizona ${ }^{4}$} \\
\hline LD 14:10 & - & $121.0 \pm 69.8(31)$ & $130.1 \pm 54.9(20) \mathrm{a}$ & $33.3 \%(6)$ & $20.4 \pm 2.0(12)$ \\
\hline LD 13:11 & - & - & $125.4 \pm 46.7(7) \mathrm{a}$ & $87.5 \%(8)$ & - \\
\hline LD 12:12 & - & - & $161.7 \pm 50.3(12) \mathrm{a}$ & $66.6 \%(18)$ & - \\
\hline LD 10:14 & - & - & $221.0 \pm 40.9(67) b$ & $90.5 \%(74)$ & - \\
\hline \multicolumn{6}{|c|}{ Shasta Lake, California ${ }^{5,6}$} \\
\hline LD 16:8 & $9.0 \pm 1.3(21) \mathrm{a}$ & $7.9 \pm 0.6(21) \mathrm{a}$ & $9.0 \pm 0(8)$ & $38.1 \%(21)$ & - \\
\hline LD $14: 10$ & $10.0 \pm 0.9(12) b$ & $19.2 \pm 2.7(5) \mathrm{c}$ & $45,108(2)$ & $16.6 \%(12)$ & - \\
\hline LD 13:11 & $8.5 \pm 0.5(13) \mathrm{a}$ & $10.3 \pm 1.1(13) \mathrm{b}$ & $174-214(3)$ & $15.4 \%(13)$ & $17.0 \pm 0(2)$ \\
\hline LD 12:12 & $8.5 \pm 0.5(13) a$ & $9.6 \pm 1.1(10) b$ & $147,194(2)$ & $15.4 \%(13)$ & - \\
\hline LD 10:14 & Not tested & & & & \\
\hline \multicolumn{6}{|c|}{ Redding, California } \\
\hline LD 16:8 & $7.8 \pm 0.5(16) \mathrm{a}$ & $7.3 \pm 0.5(15) \mathrm{a}$ & $8.9 \pm 1.3(14) \mathrm{a}$ & $62.5 \%(24)$ & $18.9 \pm 1.8(7) \mathrm{a}$ \\
\hline LD 14:10 & $9.6 \pm 0.9(15) b$ & $24.5 \pm 9.0(15) \mathrm{ab}$ & $126.5 \pm 24.7(6) b$ & $65.0 \%(20)$ & $18.8 \pm 2.6(11) \mathrm{a}$ \\
\hline LD 12:12 & $9.1 \pm 0.8(17) b$ & $33.8 \pm 40.4(9) \mathrm{b}$ & $128.7 \pm 57.3(15) \mathrm{b}$ & $56.0 \%(18)$ & $18.7 \pm 3.1(10) \mathrm{a}$ \\
\hline LD 10:14 & $8.1 \pm 0.3(12) \mathrm{a}$ & $22.0 \pm 18.0(10) \mathrm{ab}$ & $131.0 \pm 42.8(8) b$ & $53.3 \%(15)$ & $22.6 \pm 3.9(5) \mathrm{a}$ \\
\hline \multicolumn{6}{|c|}{ Kings Canyon, California } \\
\hline LD 16:8 & - & $7.6 \pm 0.6(25) \mathrm{a}$ & $11.1 \pm 2.1(24) \mathrm{a}$ & $96.0 \%(25)$ & $20.0 \pm 0.9(22) b c$ \\
\hline LD 14:10 & - & $13.5 \pm 7.5(20) \mathrm{a}$ & $64.9 \pm 54.9(20) b$ & $80 \%(25)$ & $18.7 \pm 1.5(19) \mathrm{ab}$ \\
\hline LD 12:12 & - & $9.2 \pm 1.1(27) \mathrm{a}$ & $118.7 \pm 19.6(24) c$ & $88.9 \%(27)$ & $21.3 \pm 2.8(24) \mathrm{c}$ \\
\hline LD 10:14 & - & $29.4 \pm 31.9(24) b$ & $84.0 \pm 25.6(24) b$ & $96.0 \%(25)$ & $18.8 \pm 4.3(22) \mathrm{a}$ \\
\hline \multicolumn{6}{|c|}{ Pseudomallada sierra } \\
\hline LD 16:8 & $8.7 \pm 0.8(29) \mathrm{c}$ & $7.9 \pm 0.7(29) \mathrm{a}$ & $7.3 \pm 0.8(43) \mathrm{a}$ & $100 \%(29)$ & $17.4 \pm 1.1(38) \mathrm{a}$ \\
\hline LD $14: 10$ & $7.9 \pm 0.4(22) b$ & $13.5 \pm 1.7(27) b$ & $162.0 \pm 44.1(7) \mathrm{d}$ & $13.0 \%(23)$ & $18.0 \pm 1.4(2) \mathrm{a}$ \\
\hline LD 12:12 & $7.1 \pm 0.5(22) \mathrm{a}$ & $8.0 \pm 0.9(22) \mathrm{a}$ & $126.7 \pm 48.5(19) \mathrm{c}$ & $82.6 \%(23)$ & $17.9 \pm 1.8(8) \mathrm{a}$ \\
\hline LD 10:14 & $7.5 \pm 0.5(17) \mathrm{ab}$ & $7.7 \pm 0.6(29) \mathrm{a}$ & $104.5 \pm 23.7(11) b$ & $21.7 \%(23)$ & $18.5 \pm 1.7(10) \mathrm{a}$ \\
\hline
\end{tabular}

${ }^{1}$ Deaths occurred after 150 days as third instars. ${ }^{2}$ Deaths occurred after 82-236 days as second instars. ${ }^{3}$ Most deaths occurred after 176 days as third instars. ${ }^{4}$ The Huachuca Mts population was not tested under LD 16:8. Several individuals reared at that photoperiod completed development within $\sim 45$ days. This duration is similar to those of nondiapausing individuals from other populations (Table 2 ). ${ }^{5}$ Survival was low probably because of poor quality larval diet. ${ }^{6}$ Third instar numbers too low for statistical test. 
TABLE 4. Photoperiodic influence on the duration of larval diapause in Pseudomallada perfectus [Temperature: $23.9 \pm 1.0^{\circ} \mathrm{C}$; Free living third instar (L3) developmental time = days from L2-L3 molt to cocoon formation; cocoon = prepupal L3 + pupa]. Within each population and within each column, values followed by same letter are not significantly different (ANOVA, with Bonferroni test, $\mathrm{p}<0.05$ ).

\begin{tabular}{lcll}
\hline $\begin{array}{l}\text { Locality; Diapausing stage } \\
\text { Photoperiod }\end{array}$ & $\begin{array}{c}\text { Free-living L3 developmental } \\
\text { time, Mean } \pm \mathrm{SD} \text {, days }(\mathrm{n})^{1}\end{array}$ & $\begin{array}{l}\text { L3 survival rate }(\mathrm{n}) \\
\text { [age at death, days] }\end{array}$ & $\begin{array}{c}\text { Time within cocoon } \\
\text { Mean } \pm \mathrm{SD}, \text { days }(\mathrm{n})\end{array}$ \\
\hline
\end{tabular}

A. Redding, California; Third instar (transfers to photoperiod \#2 at age $34 \mathrm{~d}$ )

$\begin{array}{lccc}\text { LD } 10: 14 & 131.0 \pm 42.8(8) \mathrm{a} & 75.0 \%(12)[210-300] & 20.6 \pm 4.8(5) \\ \text { LD } 10: 14 \rightarrow \text { LD 16:8 } & 56.9 \pm 2.0(7) \mathrm{b} & 100 \%(7) & 18.8 \pm 1.8(6) \\ \text { LD } 12: 12 & 128.7 \pm 57.3(15) \mathrm{a} & 83.3 \%(15)[160] & 18.7 \pm 3.1(10) \\ \text { LD 12:12 } \rightarrow \text { LD 16:8 } & 56.7 \pm 5.9(13) \mathrm{b} & 100 \%(13) & 21.8 \pm 1.7(11) \\ \text { LD 14:10 } & 126.5 \pm 24.7(6) \mathrm{a} & 75.0 \%(80)[94,183] & 17.8 \pm 1.6(5) \\ \text { LD 14:10 } \rightarrow \text { LD 16:8 } & 52.5 \pm 4.8(6) \mathrm{b} & 100 \%(7) & 21.3 \pm 1.0(7) \\ \text { LD 16:8 } & 8.9 \pm 1.3(14) \mathrm{c} & 100 \%(15) & 18.9 \pm 1.8(7)\end{array}$

Free-living L3: ANOVA $-\mathrm{F}=27.317538, \mathrm{p}<0.0001$, d.f., $=70$.

Cocoon: ANOVA $-\mathrm{F}=3.2365536, \mathrm{p}=0.01011$, d.f. $=50$; Bonferroni test: no significant differences between treatments.

\begin{tabular}{lccl}
\hline B. Huachuca Mts, Arizona; Third Instar (transfers to photoperiod \#2 at age $10 \mathrm{~d})$ & \\
LD $10: 14 \rightarrow-$ & $199.5 \pm 50.7(4) \mathrm{ab}$ & $57.1 \%(7)[302-407]$ & - \\
LD $10: 14 \rightarrow$ LD 12:12 & $128.6 \pm 42.6(5) \mathrm{bc}$ & $83.3 \%(6)[271]$ & - \\
LD $10: 14 \rightarrow$ LD 14:10 & $47.0 \pm 13.7(6) \mathrm{d}$ & $100 \%(6)$ & - \\
LD $10: 14 \rightarrow$ LD 16:8 & $59.6 \pm 24.6(5) \mathrm{cd}$ & $100 \%(5)$ & - \\
LD $13: 11 \rightarrow$ LD 10:14 & $269.7 \pm 41.4(3) \mathrm{a}$ & $75.0 \%(4)[341]$ & - \\
LD 13:11 & $141.4 \pm 46.7(7) \mathrm{b}$ & $100 \%(7)$ & - \\
LD 13:11 $\rightarrow$ LD 14:10 & $38.8 \pm 9.8(4) \mathrm{d}$ & $100 \%(4)$ & - \\
LD 13:11 $\rightarrow$ LD 16:8 & $33.7 \pm 5.8(3) \mathrm{d}$ & $75.0 \%(4)[278]$ &
\end{tabular}

Free-living L3: ANOVA $-\mathrm{F}=22.537608, \mathrm{p}<0.0001$, d.f., $=36$

${ }^{1}$ Developmental time $=$ total number of days for third instar development (from molt to cocoon spinning), not the number of days from the transfer to LD 16:8 until cocoon spinning.

tion, and 10-day-old, diapausing third-instar F2 offspring from the Huachuca Mtn, AZ population.

The second experiment examined the effects of photoperiod and low temperature on diapausing larvae that had been reared under LD $10: 14,23.9^{\circ} \mathrm{C}$ (Table 5). It had two sets of treatments and four conditions (see Table 5). Treatment \#1 was initiated 26 days after larvae had molted to the third instar and continued until 64 days post-molt. During this treatment, all larvae experienced the same constant short daylength (LD 10:14); but, half of the larvae (Conditions $1 \& 3)$ were exposed to low temperature $\left(4.4^{\circ} \mathrm{C}\right)$ and the other half (Conditions $5 \& 7$ ) remained at $23.9^{\circ} \mathrm{C}$. In Conditions 1 and 3 , the transfer from the warm to the cool regimen $\left(23.9^{\circ} \mathrm{C}\right.$ to $\left.4.4^{\circ} \mathrm{C}\right)$ was done stepwise: on day 26 the larvae were transferred to $15.6^{\circ} \mathrm{C}$ where they remained for 4 days; on day 30 they were transferred to $10^{\circ} \mathrm{C}$ for 4 days; and then, on day 34 they were moved to $4.4^{\circ} \mathrm{C}$ where they remained for 30 days.

Treatment \#2 began immediately after Treatment \#1 (day 64 post-molt). During Treatment \#2, all larvae experienced the same temperature (constant $23.9^{\circ} \mathrm{C}$ ); but, half of the larvae from each of the regimens in Treatment \#1 (Conditions $1 \& 5$ ) remained under short daylength (LD 10:14), and the other half (Conditions 3 \& 7) was transferred to long daylengths (LD 16:8). The transfer from cool to warm conditions occurred in an abrupt, single change.

This experiment involved the Redding, CA populations of $P$. perfectus and $P$. sierra, as well as one hybrid genotype ( $\mathrm{SP}=P$. sierra mother $\times P$. perfectus father) [See "3. Interspecific hybrids ...", below]. Note: The test with the SP hybrid genotype differed from the above in the timing of the treatments; i.e. Treatment \#1 began on day 30 of larval life, and Treatment \#2 followed immediately afterwards, beginning on day 96 (Table 5).
3. Interspecific hybrids - diapause-related responses (Table 6)

In an earlier study, we had determined that $P$. perfectus $(\mathrm{P})$ and P. sierra (S) could hybridize and produce viable (but infertile) offspring (Tauber \& Tauber, in prep.). Here, we examined how the F1 hybrids respond to photoperiodic conditions that induce and maintain diapause in the parental genotypes.

Our test began with intraspecific and interspecific pairings of first generation, lab-reared adults - four of $P$. sierra $(\mathrm{S} \times \mathrm{S})$, nine of $P$. perfectus $(\mathrm{P} \times \mathrm{P})$, one of $P$. perfectus $q \times P$. sierra $\hat{O}(\mathrm{P} \times$ $\mathrm{S})$ cross, and two of $P$. sierra $\bigcirc \times P$. perfectus $\delta(\mathrm{S} \times \mathrm{P})$. This experiment was identical to and concurrent with the "Diapause induction - photoperiod" experiment described above; the data for P. sierra and P. perfectus (Redding, CA), reported on Table 3, represent the results for the parental population.

\section{Development - temperature}

The thermal requirements for development and the initiation of reproduction were examined for one population of $P$. perfectus [Kings Canyon, CA]. Eggs were distributed among five constant temperatures $\left(15.6\right.$ to $\left.26.7^{\circ} \mathrm{C}\right)$ at LD $16: 8$ (Table 7); each condition began with 29-46 individuals. Rearing procedures were as described above. We recorded larval molts, cocoon spinning, adult emergence, and deaths. The prepupal stage was defined as the period from cocoon spinning to the larval-pupal molt within the cocoon; the preoviposition period was the time from female emergence to first oviposition. Newly emerged females and males were paired and maintained under the temperatures at which they were reared. If an adult died before oviposition occurred, the surviving partner received a new mate.

For each life stage we analyzed the effect of temperature on development by first plotting developmental rate [1/developmental time (1/days)] against temperature. We estimated " $t_{\mathrm{d} \min }$ ", the minimum temperature for development $[=$ lower developmental threshold (t), lower developmental temperature (LDT), or basal 
TABLE 5. Effect of photoperiod and chilling on the developmental time (to cocoon formation) of diapausing third instars - Pseudomallada perfectus, P. sierra, and an F1 hybrid. Parental populations from Redding, California.

\begin{tabular}{|c|c|c|c|c|}
\hline \multicolumn{5}{|c|}{ Experimental conditions } \\
\hline Condition & \multicolumn{2}{|c|}{ Treatment \#1 } & \multicolumn{2}{|c|}{ Treatment \#2 } \\
\hline 1. & LD 10:14 & $4.4^{\circ} \mathrm{C}^{1}$ & LD 10:14 & $23.9^{\circ} \mathrm{C}$ \\
\hline 3. & LD 10:14 & $4.4^{\circ} \mathrm{C}$ & LD $16: 8$ & $23.9^{\circ} \mathrm{C}$ \\
\hline 5. & LD 10:14 & $23.9^{\circ} \mathrm{C}$ & LD 10:14 & $23.9^{\circ} \mathrm{C}$ \\
\hline 7. & LD 10:14 & $23.9^{\circ} \mathrm{C}$ & LD 16:8 & $23.9^{\circ} \mathrm{C}$ \\
\hline \multicolumn{5}{|c|}{ Experimental results } \\
\hline \multicolumn{2}{|c|}{$\begin{array}{l}\text { L3 duration after start of Treatment \#2, } \\
\text { Mean } \pm \text { SD, days (n) }\end{array}$} & \multicolumn{2}{|c|}{$\begin{array}{c}\text { L3 total duration, } \\
\text { Mean } \pm \text { SD, days (n) }\end{array}$} & $\begin{array}{c}\% \text { cocoon } \\
\text { formation }(n)\end{array}$ \\
\hline \multicolumn{5}{|c|}{ Pseudomallada perfectus ${ }^{2,3}$} \\
\hline 1. $74.6 \pm 3$ & & \multicolumn{2}{|c|}{$168.5 \pm 35.5(9) \mathrm{c}$} & $100(10)$ \\
\hline 3. $21.9 \pm 6$ & & \multicolumn{2}{|c|}{$118.5 \pm 16.5(8) b$} & $100(8)$ \\
\hline 5. $92.7 \pm 3$ & & \multicolumn{2}{|c|}{$144.3 \pm 47.9(8) \mathrm{bc}$} & $53(15)$ \\
\hline 7. $31.7 \pm 4$ & & \multicolumn{2}{|c|}{$57.9 \pm 2.0(7) \mathrm{a}$} & $88(8)$ \\
\hline \multicolumn{5}{|c|}{ Pseudomallada sierra ${ }^{2,4}$} \\
\hline 1. $47.0 \pm 1$ & & \multicolumn{2}{|c|}{$130.2 \pm 23.4(13) \mathrm{c}$} & $86(14)$ \\
\hline 3. $13.4 \pm 2$ & & \multicolumn{2}{|c|}{$91.8 \pm 3.1(14) \mathrm{a}$} & $100(14)$ \\
\hline 5. $70.0 \pm 1$ & & \multicolumn{2}{|c|}{$104.5 \pm 23.7(11) b$} & $78(14)$ \\
\hline \multicolumn{5}{|c|}{ 7. Not included } \\
\hline \multicolumn{5}{|c|}{ Pseudomallada sierra-perfectus F1 (SP) hybrid ${ }^{5,6}$} \\
\hline 1. $48.8 \pm 2$ & & \multicolumn{2}{|c|}{$210.1 \pm 19.0(11) a$} & $100(13)$ \\
\hline 3. $14.5 \pm 5$ & & \multicolumn{2}{|c|}{$110.2 \pm 5.9(9) b$} & $100(13)$ \\
\hline 5. $57.6 \pm 1$ & & \multicolumn{2}{|c|}{$111.3 \pm 17.2(12) b$} & $100(12)$ \\
\hline 7. $13.6 \pm 2$ & & \multicolumn{2}{|c|}{$46.0 \pm 3.2(10) \mathrm{c}$} & $100(14)$ \\
\hline
\end{tabular}

${ }^{1}$ Transfer from $23.9^{\circ} \mathrm{C}$ to $4.4^{\circ} \mathrm{C}$ was step-wise (See Material \& Methods); the reciprocal transfer at the initiation of Treatment \#2 was in one step. ${ }^{2}$ Treatment \#1 extended from days 26-64; Treatment \#2 began on day 64 . ${ }^{3}$ Photoperiod, but not temperature, had a significant effect on the duration of diapause [ANOVA, with Bonferroni test: L3 duration after start of Treatment \#2, Temp: $\mathrm{F}=0.897, \mathrm{P}=0.3538$; Photoperiod: $\mathrm{F}=47.420, \mathrm{P}<0.0001$; Interaction: $\mathrm{F}=0.001, \mathrm{p}=0.1975$; d.f. $=27]$. ${ }^{4}$ Both temperature and photoperiod had significant effects on the duration of diapause [Student t-test: L3 duration after start of Treatment $\# 2$, Condition 1 versus $3, t=7.3743, p<0.0001$, d.f. $=22$; Condition 1 versus $5, \mathrm{t}=4.8315, \mathrm{p}<0.0001$, d.f. $=37$; Condition 3 versus $5, \mathrm{t}=0.4989, \mathrm{p}=0.623$, d.f. $=21$; $\mathrm{L} 3$ total duration, Condition 1 versus $3, \mathrm{t}=5.997, \mathrm{p}<0.0001$, d.f. $=25$; Condition 1 versus $5, \mathrm{t}=2.6414, \mathrm{p}=0.01491$, d.f. $=22]$; Condition 3 versus 5 , $\mathrm{t}=-1.9871, \mathrm{p}=0.05895$, d.f. $=23] .{ }^{5}$ Treatment $\# 1$ extended from days 30-96; Treatment $\# 2$ began on day $96 .{ }^{6}$ Both temperature and photoperiod had significant effects on the duration of diapause, as well as a significant interaction [ANOVA, Temp: $\mathrm{F}=350.075, \mathrm{P}<$ 0.0001; Photoperiod: $\mathrm{F}=360.370, \mathrm{P}<0.0001$; Interaction: $\mathrm{F}=16.787, \mathrm{p}=0.0002$; d.f. $=39$ ].

temperature $\left(\mathrm{T}_{\mathrm{b}}\right)$ of other authors] by extrapolating the regression line between developmental rate and temperature to the $\mathrm{x}$-axis. Then, we estimated $\mathrm{K}$, the number of heat degree-days for completion of development $[=$ HDD, or sum of effective temperatures (SET) of other authors] from the equation, $K=1 / m$, where $\mathrm{m}$ is the slope of the regression line.

We used "KaleidaGraph", Version 4.5, Synergy Software, to quantify the above linear relationships. Also, because some of the developmental rates appeared not to be linearly related to temperature, we also used "KaleidaGraph" to fit a smooth curve to the data. This calculation first applies a Stineman function to the data. The output of this function then has a geometric weight applied to the current point and $\pm 10 \%$ of the data range, to arrive at the smoothed curve. There is no single expression that represents this curve; therefore, there are no parameters, and we did not report $\mathrm{t}_{\mathrm{d} \text { min }}$ or $\mathrm{K}$ values for life stages with nonlinear data.

\section{RESULTS}

All three Pseudomallada species underwent uninterrupted development (oviposition to adult emergence) when immatures were reared under long-day conditions (LD 16:8) (Table 2). Developmental times averaged 41-50 days (at $23.9^{\circ} \mathrm{C}$ ), and diapause was absent (although third instar development was slightly prolonged in some individuals).

\section{Diapause induction - photoperiod}

\section{(a) Survival}

In all but one population that we tested, survival rates were high (60-100\%) under nondiapause conditions (LD 16:8). In some (e.g., the two populations of P. macleodi, from Kansas and Texas), diapause was associated with low survival $(<20 \%)$; in others (e.g., Kings Canyon and Redding, CA populations of $P$. perfectus) survival was relatively high (50-100\%) across all photoperiods.

\section{(b) Critical photoperiod for diapause induction}

For all species and populations, the three photoperiods shorter than LD 16:8 delayed development and induced diapause in all third instars (Table 3 ). Thus, the critical photoperiod fell between LD 14:10 and LD 16:8 $\left(23.9^{\circ} \mathrm{C}\right)$.

\section{(c) Photoperiod - diapause duration}

Among the tested populations of $P$. macleodi and P. perfectus (except the Redding, CA population), daylengths below the critical photoperiod had significant effects on the duration of diapause. Moreover, the pattern of effects was not consistent either among the Pseudomallada species, or among the geographic populations of $P$. perfectus (Table 
TABLe 6. Photoperiodic influence on preimaginal development in F1 Pseudomallada perfectus, P. sierra, and their interspecific hybrids. [Temperature: $23.9 \pm 1.0^{\circ} \mathrm{C}$; L1-L3 = instar number]. Within each row, values followed by same letter are not significantly different; values in rows without letters do not vary significantly (ANOVA, with Bonferroni test, $\mathrm{p}<0.05$ ). Parental populations from Redding, California.

\begin{tabular}{|c|c|c|c|c|c|}
\hline & & P. perfectus (PP) & P. sierra $(\mathrm{SS})$ & P. perfectus-sierra (PS) & . sierra-perfectus (SP) \\
\hline \multicolumn{6}{|c|}{ Larval developmental time, Mean \pm SD, days (n) } \\
\hline \multirow[t]{4}{*}{ L1 } & LD 16:8 & $7.8 \pm 0.5(16)$ & $8.7 \pm 0.8(29)$ & $8.5 \pm 0.5(6)$ & $8.2 \pm 1.0(19)$ \\
\hline & LD 14:10 & $9.6 \pm 0.9(15) \mathrm{b}$ & $7.9 \pm 0.4(22) \mathrm{a}$ & $9.0 \pm 0(5) b$ & $9.1 \pm 0.7(22) b$ \\
\hline & LD 12:12 & $9.1 \pm 0.8(17) \mathrm{c}$ & $7.1 \pm 0.5(22) \mathrm{a}$ & - & $8.0 \pm 0.5(25) b$ \\
\hline & LD 10:14 & $8.1 \pm 0.3(12)$ & $7.5 \pm 0.5(17)$ & $8.2 \pm 0.7(13)$ & $7.7 \pm 0.5(24)$ \\
\hline \multirow[t]{4}{*}{ L2 } & LD 16:8 & $7.3 \pm 0.5(15) \mathrm{a}$ & $7.9 \pm 0.7(29) b$ & $6.7 \pm 0.5(6) \mathrm{a}$ & $6.7 \pm 0.7(19) \mathrm{a}$ \\
\hline & LD 14:10 & $24.5 \pm 9.0(15) \mathrm{a}$ & $13.5 \pm 1.7(27) b$ & $18.0 \pm 8.5(4) \mathrm{ab}$ & $15.4 \pm 2.5(22) b$ \\
\hline & LD 12:12 & $33.8 \pm 40.4(9) \mathrm{a}$ & $8.0 \pm 0.9(22) b$ & - & $9.2 \pm 0.8(25) \mathrm{b}$ \\
\hline & LD 10:14 & $22.0 \pm 18.0(10) \mathrm{a}$ & $7.7 \pm 0.6(29) b$ & $9.5 \pm 0.8(13) b$ & $8.6 \pm 1.2(24) b$ \\
\hline \multirow[t]{4}{*}{ Free-living L3 } & LD 16:8 & $8.9 \pm 1.3(14) \mathrm{c}$ & $7.3 \pm 0.8(43) \mathrm{ab}$ & $8.2 \pm 1.0(6) b c$ & $6.7 \pm 0.9(19) \mathrm{a}$ \\
\hline & LD 14:10 & $126.5 \pm 24.7(6) \mathrm{a}$ & $162.0 \pm 44.1(7) \mathrm{a}$ & $272.3 \pm 37.8(3) b$ & $241.3 \pm 65.2(8) b$ \\
\hline & LD 12:12 & $128.7 \pm 57.3(15)$ & $126.7 \pm 48.5(19)$ & - & $169.5 \pm 16.1(10)$ \\
\hline & LD 10:14 & $131.0 \pm 42.8(8) \mathrm{a}$ & $104.5 \pm 23.7(11) \mathrm{a}$ & $178.3 \pm 7.5(6) \mathrm{b}$ & $111.3 \pm 17.1(12) \mathrm{a}$ \\
\hline \multicolumn{6}{|c|}{ Larval survival rate $(\mathrm{n})$} \\
\hline & LD 16:8 & $62.5 \%(24)$ & $100 \%(29)$ & $100 \%(6)$ & $100 \%(19)$ \\
\hline & LD 14:10 & $65.0 \%(20)$ & $13.0 \%(23)$ & $60 \%(5)$ & $36.4 \%(22)$ \\
\hline & LD 12:12 & $56.0 \%(18)$ & $82.6 \%(23)$ & - & $83.3 \%(12)$ \\
\hline & LD 10:14 & $53.3 \%(15)$ & $21.7 \%(23)$ & $38 \%(13)$ & $100 \%(12)$ \\
\hline
\end{tabular}

3). In one (e.g., P. perfectus, Huachuca Mts, AZ), LD 10:14 induced a more persistent (thus deeper) diapause than did the other (longer) diapause-inducing short daylengths tested. And, in the Kings Canyon, CA population, LD 12:12 induced the longest diapause. However, in the Redding, CA population, diapause duration did not vary significantly among the short-day, diapause-inducing photoperiods. Notably, for the single $P$. sierra population (Redding, CA), LD 10:14 resulted in a shorter diapause than any of the other photoperiods tested.

(d) Photoperiod - prediapause and postdiapause stages

First instars of all three species showed very small, but significant differences in developmental times under the photoperiods tested. The pattern of variation was not consistent across species or populations.

In comparison, second instars of all the species had significant and relatively large developmental delays under at least one of the short-day photoperiods. For example, in $P$. macleodi and $P$. sierra, development of second instars was prolonged only at LD 14:10, not at LD 12:12 or LD 10:14 (Table 3). In P. perfectus, the populations varied as to which short day(s) caused the delay in second instar development. In the Shasta Lake, CA population LD 14:10 was most effective, but LD 12:12 and LD 10:14 also caused significant developmental delays. In contrast, a delay occurred only under LD 12:12 in the Redding, CA population, and only under LD 10:14 in the Kings Canyon, CA population.

In this test, the postdiapause/nondiapause prepupal and pupal periods within the cocoon typically ranged between 17 and 23 days for all the species. Although this period varied significantly among photoperiodic treatments, we did not discern a specific relationship with the daylengths tested (Table 3).

\section{Diapause termination - photoperiod, temperature}

First experiment

The first experiment dealing with diapause termination used two populations of $P$. perfectus (Redding, CA and Huachuca Mts, AZ), and it addressed three aspects of diapause: (a) whether an increase in daylength would hasten the termination of diapause, (b) whether a decrease in daylength would intensify diapause, and thus prolong its duration, and (c) whether photoperiod affected the rate of postdiapause development within the cocoon. Although the results were consistent in this experiment, the numbers were relatively small, and we consider that the findings are preliminary.

(a) Increase in daylength and diapause termination

Larvae from two $P$. perfectus populations (Redding, CA and Huachuca Mts, AZ) were tested. In both populations, the transfer of diapausing third instars from a diapauseinducing daylength (LD 10:14, 12:12, 13:11, or 14:10) to the long daylength of LD 16:8 resulted in a significant and substantial ( $>60$ day) reduction in the total time for third instars to develop (Table 4A, B). However, the response time (= the time to initiate spinning after the transfer to LD 16:8) was long; for example, in the Redding, CA population, cocoon spinning occurred $\sim 18-21$ days after the transfer of diapausing third instars to LD 16:8 (Table 4A). This value is roughly twice the $\sim 9$-day average that nondiapause third instars require before they spin (at constant LD 16:8 and the same temperature, $23.9^{\circ} \mathrm{C}$ ).

The experimental procedure with the Huachuca Mts, AZ larvae differed from the one above in that cohorts of diapausing larvae were subjected to increases in daylengths (of two or four hours) that remained below the critical photoperiod for diapause induction, as well as one (of six hours) that crossed the critical photoperiod. That is, larvae 
TABLE 7. Survival and thermal requirements for Pseudomallada perfectus development and reproduction (Kings Canyon, California population, lab-reared F2, LD 16:8). All temperatures were $\pm 1^{\circ} \mathrm{C}$; $\mathrm{t}_{\mathrm{d} \text { min }}$, lower thermal threshold for development; K (HDD), number of heat-degree days above $\mathrm{t}_{\mathrm{d} \text { min }}$ that are required for completion of development.

\begin{tabular}{|c|c|c|c|c|c|c|c|}
\hline & \multicolumn{5}{|c|}{ Development, Mean \pm SD days } & \multicolumn{2}{|c|}{ Thermal requirements } \\
\hline & $15.6^{\circ} \mathrm{C}$ & $18.3^{\circ} \mathrm{C}$ & $21^{\circ} \mathrm{C}$ & $23.9^{\circ} \mathrm{C}$ & $26.7^{\circ} \mathrm{C}$ & $\mathrm{t}_{\mathrm{d} \min }\left({ }^{\circ} \mathrm{C}\right)$ & $\mathrm{K}(\mathrm{HDD})^{1}$ \\
\hline Egg & $18.7 \pm 1.2$ & $13.8 \pm 0.4$ & $10.2 \pm 0.4$ & $8.0 \pm 0$ & $5.9 \pm 0.3$ & 11.1 & 96.1 \\
\hline First instar & $17.4 \pm 0.1$ & $14.6 \pm 0.7$ & $12.1 \pm 1.6$ & $9.2 \pm 1.1$ & $7.1 \pm 1.2$ & - & - \\
\hline Second instar & $14.0 \pm 0.8$ & $11.5 \pm 0.8$ & $12.1 \pm 2.4$ & $7.8 \pm 0.7$ & $6.2 \pm 0.7$ & - & - \\
\hline Free-living third instar & $18.8 \pm 2.4$ & $14.7 \pm 1.4$ & $13.7 \pm 2.3$ & $11.8 \pm 3.1$ & $10.4 \pm 3.5$ & - & - \\
\hline Prepupa + Pupa & $42.6 \pm 2.8$ & $34.1 \pm 1.2$ & $27.0 \pm 0.9$ & $21.5 \pm 0.7$ & $16.7 \pm 0.6$ & 9.1 & 305.9 \\
\hline Total & $111.0 \pm 4.9$ & $88.5 \pm 3.0$ & $72.2 \pm 3.2$ & $59.0 \pm 3.8$ & $46.2 \pm 4.6$ & 8.3 & 875.4 \\
\hline Number tested (min.) & 24 & 22 & 30 & 30 & 34 & & \\
\hline$\%$ survival to adult & 60.9 & 81.5 & 68.2 & 69.6 & 76.1 & & \\
\hline Sex ratio $(\mathrm{F}: \mathrm{M})$ & $1.6: 1$ & $0.91: 1$ & $1.5: 1$ & $0.9: 1$ & $0.6: 1$ & & \\
\hline Fertile oviposition, \% (n pairs) & $0(13)$ & $60(10)$ & $75(12)$ & $92(13)$ & $100(11)$ & & \\
\hline $\begin{array}{l}\text { Previposition period } \\
\text { Mean } \pm \operatorname{SD}(n)^{2}\end{array}$ & - & $\begin{array}{l}19.2 \pm 2.0 \\
(6)\end{array}$ & $\begin{array}{l}16.2 \pm 3.7 \\
\text { (9) }\end{array}$ & $\begin{array}{l}12.8 \pm 5.0 \\
\quad(12)\end{array}$ & $\begin{array}{l}11.7 \pm 3.2 \\
\quad(11)\end{array}$ & 6.0 & 218.9 \\
\hline
\end{tabular}

${ }^{1}$ Calculated only for stages in which developmental rates were linearly related to temperature.

${ }^{2}$ Within each temperature, there was considerable variation in the developmental rates leading to oviposition; thus, the $\mathrm{R}$ value of the linear regression line was low $(\mathrm{R}=0.58096)$. However, a linear relationship appeared to be an appropriate fit for the data.

were transferred from LD 10:14 (below the critical photoperiod) to either LD 12:12 or LD 14:10 (also below the critical photoperiod), or LD 16:8 (above the critical photoperiod) (see Table 4). In this experiment, developmental times showed a quantitative and inverse relationship with the final daylength. Development was slowest under constant LD 10:14, intermediate after the transfer to LD 12:12, and fastest after transfer to LD 14:10 or LD 16:8 (Table 4B, upper four treatments).

In the second group from the Huachuca Mts, AZ, larvae were transferred from LD 13:11 to either of two longer daylengths (one below the critical photoperiod for diapause induction - LD 14:10, and one above it - LD 16:8). After the transfer, larvae in LD 14:10 and LD 16:8 developed at similar rates and significantly faster than those that remained under LD 13:11 (Table 4B, lower four treatments).

(b) Decrease in daylength and diapause prolongation

In conjunction with the test above, one treatment (with the P. perfectus, Huachuca Mts, AZ population) examined the effect of a decrease in daylength (below the critical photoperiod) on the duration of diapause. In this case, larvae that had been reared and in which diapause had been induced under LD 13:11, were transferred to LD 10:14. The resulting developmental time was significantly longer than that at constant LD 13:11 (Table 4B, lower four treatments).

(c) Photoperiod - postdiapause development within the cocoon

The time for postdiapause larval and pupal development within the cocoon showed significant variation among treatments in the single population tested ( $P$. perfectus, Redding, CA) (Table 4A). However, the variation had no consistent relationship with the photoperiods tested.

\section{Second experiment}

This experiment, with $P$. perfectus and $P$. sierra from Redding, CA, tested the effect of photoperiod and a period of low temperature $\left(4.4^{\circ} \mathrm{C}\right.$, "chilling") on the time for diapausing larvae to complete development (= begin cocoon formation). In all treatments (whether the larvae experienced chilling or not), survival rates were relatively high, and an increase in daylength resulted in substantial, and significant, reductions in the time required for larval development (Compare Treatments 1 vs 3 and 5 vs 7; Tables 5,7 ).

Larvae that had experienced a period of chilling during diapause (Treatments 1 and 3) did not complete their development faster than those that had remained under constant warm conditions (Compare Treatments 1 vs 5 and 3 vs 7). Indeed, in some cases the total period of development prior to cocoon spinning was longer if the larvae had experienced a period of chilling during diapause than if they had not (significant differences: $P$. perfectus, Treatments 3 vs 7; $P$. sierra, Treatments 1 vs $5 ; P$. sierra $\times P$. perfectus hybrids, Treatments 1 vs 5 and 3 vs 7).

\section{Photoperiodic responses of F1 interspecific hybrids}

Our experiments above (Section 1 - Diapause induction) demonstrated how the two parental species (P. perfectus and $P$. sierra) respond to a range of constant daylengths (see Table 3). Here, to gain some insight into the genetic basis for their similarities and differences, we compare the photoperiodic responses of the parental and hybrid genotypes (see Table 6).

(a) First instars of the parental genotypes (PP, SS) expressed very small, but consistent and significant differences in their developmental responses to photoperiod. The hybrid genotypes (PS, SP) showed no consistent pattern of variation in their responses; under LD 14:10 they resembled P. perfectus (PP); under the two shorter daylengths, 
EGG

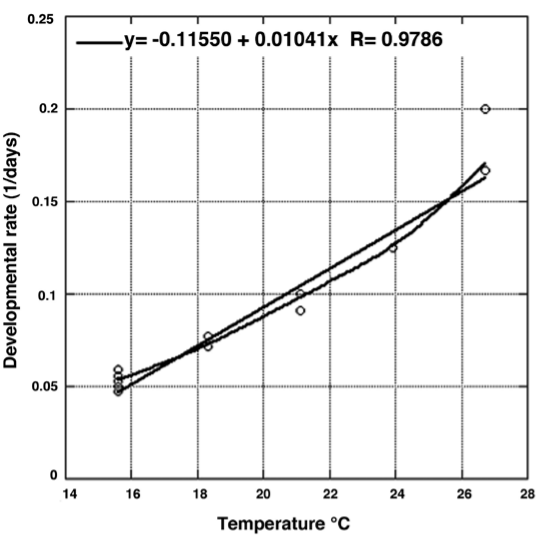

THIRD INSTAR

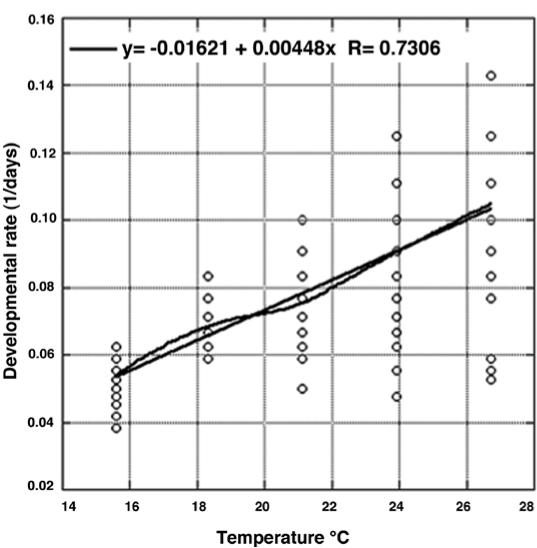

FIRST INSTAR

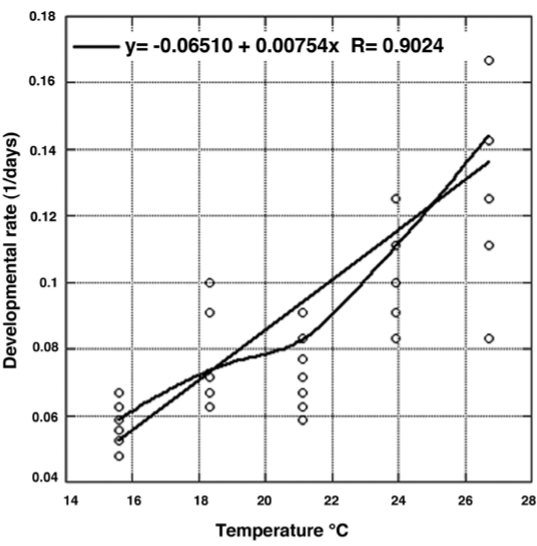

PREPUPA \& PUPA

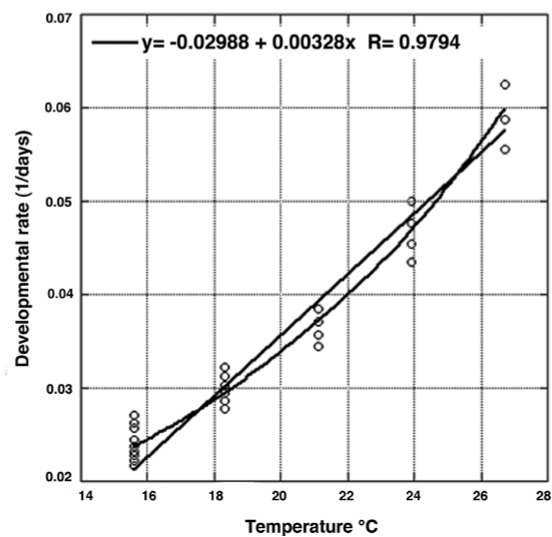

SECOND INSTAR

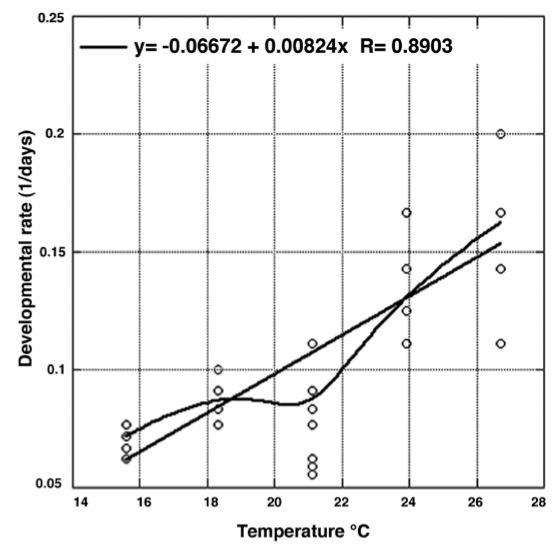

TOTAL DEVELOPMENT

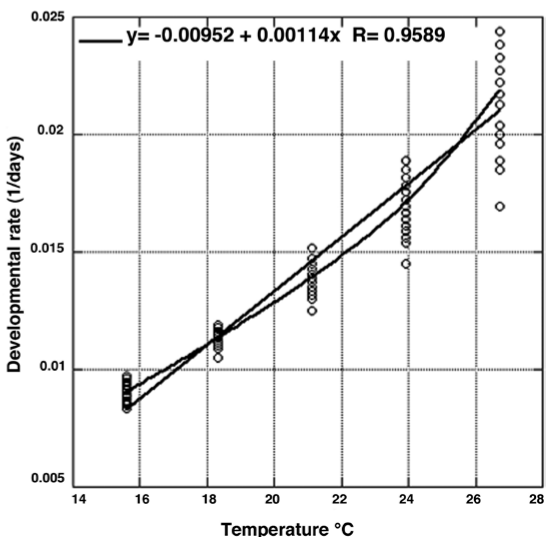

Fig. 1. The relationship between temperature and the developmental rates for each life stage of Pseudomallada perfectus (Kings Canyon, California population). Each temperature had a minimum of 22-34 data points; each marker represents one or more observations. To illustrate the patterns in the relationships, each set of data (Table 7) was fitted to a straight-line linear plot (regression equations given) and with a smoothed curve (KaleidaGraph, Version 4.5, Synergy Software).

the responses were either intermediate to the parental genotypes or they were without significant variation (Table 6).

(b) Second instars of each parental type showed distinctive developmental responses to photoperiod. In P. sierra (SS), LD 14:10 significantly delayed second instar development relative to either LD 16:8 or the two shorter daylengths, LD 12:12 or LD 10:14 (Table 3). In P. perfectus (PP), second instar development at LD 14:10 was not significantly longer than it was at the other short-day photoperiods (Table 3 ). The responses of PS and SP second instars resembled those of SS more closely than those of PP.

(c) Third instar hybrid larvae (PS, SP) expressed an unusually long (and significant) delay in development at LD 14:10 relative to the parental types. Development was $\sim 3$ months longer in each hybrid cohort than in the parental cohorts (Table 6). This pattern also occurred at LD 10:14 in the SP hybrid, but not the PS hybrid.

(d) Survival of the hybrids during rearing was variable, as it was for the parental cohorts (Table 6).

\section{Development - temperature}

Survival rates of $P$. perfectus (Kings Canyon, CA) at the five temperatures tested $\left(15.6-26.7^{\circ} \mathrm{C}\right)$ showed little variation - they ranged between 61 and $82 \%$, and there was no noticeable trend relative to temperature (Table 7).
The average time for total development (oviposition to adult emergence) ranged from $\sim 110$ days at the lowest temperature $\left(15.6^{\circ} \mathrm{C}\right)$ to $\sim 46$ days at the highest $\left(26.7^{\circ} \mathrm{C}\right)$. For the egg, prepupa-pupal period, and total life cycle, the developmental rates were positively and linearly related to temperature; the relationship was especially strong for the egg and prepupal/pupal periods, where the regression coefficients (R) were $>0.979$ (Fig. 1). The lower thresholds for development $\left(\mathrm{t}_{\mathrm{d} \text { min }}\right)$ of these stages ranged between 8 and $11^{\circ} \mathrm{C}$; the thermal requirement $(\mathrm{K})$ for total development was approximately 875 heat-degree days (HDD) above the threshold of $8.3^{\circ} \mathrm{C}$ (Table 7). The sex ratios of adults were variable; values ranged from 0.6:1 to $1.6: 1\left(ㅇ ㅜ{ }^{\lambda}\right.$ ) (Table 7).

In contrast to the above, the three larval stages showed considerable scatter in their developmental times, especially the third instar. Also, their temperature-developmental rate curves deviated from linear, especially so in the second instar (Fig. 1). Therefore, we did not calculate $t_{d \text { min }}$ or $\mathrm{K}$ values for the free-living larval stages.

Temperature strongly influenced the length of the preoviposition period and fertility. Although oviposition occurred at the lowest temperature $\left(15.6^{\circ} \mathrm{C}\right)$, none of the eggs were fertile. Above this temperature, the number of pairs that laid fertile eggs increased with temperature; fertility 
was $100 \%$ at $26.7^{\circ} \mathrm{C}$. The average preoviposition period (for fertile eggs) ranged from $\sim 19$ days at $18.3^{\circ} \mathrm{C}$, to $\sim 12$ days at $26.7^{\circ} \mathrm{C}$ (Table 7 ).

\section{DISCUSSION}

Pseudomallada's known pattern of geographic distribution $(>155$ species on three continents of the Old World and a meager five species in the New World - all restricted to western and midwestern North America) presented an enticing setting for our work. In this discussion we interpret our findings from three Nearctic Pseudomallada species within a comparative context - vis-à-vis western Palearctic species previously studied by others. Our goal is threefold: (i) to elucidate phenological features and responses that the Palearctic and Nearctic species share, (ii) to explore interspecific variation within the genus, and (iii) to highlight areas of research that we believe would reap tangible benefits.

We emphasize that during our discussion of shared phenological features, we avoid making broad generalizations concerning generic characteristics. Pseudomallada is a very large genus, with many described (e.g., Oswald 2013), as well as undescribed species (R.A. Pantaleoni, pers. commun.). Only a small percentage of these species, all from temperate regions, have been investigated. Many additional species occur in subtropical and tropical regions (Hölzel \& Duelli, 1990; Hölzel et al., 1994, 1997; Tsukaguchi, 1995; Brooks, 1997; Aspöck et al., 2001; Dong et al., 2004; Oswald, 2013), and their phenological features may differ considerably from those of the species studied previously or here.

In beginning our comparative evaluation, we provide a brief summary of the seasonal cycles and phenological responses of the Palearctic species that have been studied. Within this setting, we then evaluate our specific findings from the Nearctic species and make specific comparisons with Palearctic species. We conclude with some general recommendations.

\section{Phenological underpinnings}

As noted earlier, seven species of Western Palearctic Pseudomallada species are known to overwinter as freeliving larvae. Most are reported to do so only in the third instar [P. clathratus (Schneider), P. ibericus (Navás), $P$. prasinus (Burmeister) A-phenotype, P. zelleri (Schneider)], and some in the second and third instars [P. flavifrons (Brauer), P. picteti (McLachlan), P. ventralis (Curtis)]. One species apparently hibernates only in the second instar $[P$. prasinus (Burmeister), B-phenotype] (Withycombe, 1922; Principi \& Castellari, 1970; Séméria, 1977; Canard et al., 1992; Principi \& Sgobba, 1993; Volkovich, 1998).

The first of these Palearctic species to be examined experimentally was $P$. flavifrons. In a series of experiments over a $\sim 15$ year period, Principi and co-authors elucidated a complex suite of photoperiodic and thermal responses that induce and maintain larval diapause in this species (Principi et al., 1975, 1977, 1990; Principi \& Sgobba, 1985, 1987). Although diapause may occur occasionally in second instars, the experimental work focused mainly on diapause in the third-instars. Using two experimental photoperiods (a long day, LD 16:8, and a short day, LD 10:14), they showed: (i) diapause occurred in the third instar only if the second instar was exposed to short daylengths, and (ii) the length (depth) of the third instar diapause was directly related to the number of short days experienced during the second instar.

When P. flavifrons second instars were reared at short daylengths, they experienced a deceleration in the rate of development, but the delay in this instar was usually much smaller than that in the third instar. This relatively small increase in the number of short daylengths experienced by the photosensitive second instar had an important effect in that it caused a substantial increase in the depth of the third instar diapause. Temperature, too, affected the incidence and depth of diapause in this species, apparently through an interaction with the above photoperiodic response. In this case, lower temperatures lengthened the duration of the photosensitive second instar, and this increase in the amount of time under short daylengths, in turn, caused an increase in the depth of the third instar diapause.

Moreover, the studies by Principi and co-authors demonstrated: (iii) that under constant short-day conditions, diapause could terminate and postdiapause larval development could proceed towards cocoon spinning "spontaneously" (i.e., without the intervention of an apparent stimulus). However, (iv) long daylength would hasten the process.

Experiments with P. clathratus, $P$. ventralis, and P. prasinus A-phenotype elucidated life cycles that are similar to that of P. flavifrons (Principi \& Sgobba, 1993; Volkovich, 1998). Specifically, in all four species, the third instar is the predominant or only overwintering stage, and diapause is induced by short daylengths. In P. clathratus, the second instar also was identified as the primary sensitive stage for the photoperiodic induction of diapause that is expressed in the third instar. However, these three species differ from P. flavifrons, in that the development of second instars was not shown to be delayed by short daylengths.

In experiments by Canard and co-workers, the Palearctic species $P$. picteti was shown to have a somewhat different, more malleable life cycle than those of the species above (Canard et al., 1990, 1992; Canard \& Grimal, 1993). In three successive cohorts of outdoor rearings, this species showed a progression of developmental patterns. In the early-season cohort, only third instars entered an overwintering diapause; in a later cohort, second and third instars underwent overwintering, and in the last cohort, only second instars overwintered. Diapause depth appeared to vary among cohorts and among instars within cohorts, as did the responses to photoperiodic increases and decreases.

Finally, P. prasinus B-phenotype was found to enter winter as diapausing second instars (Volkovich, 1998). A variety of photoperiodic and temperature conditions [e.g., very long daylengths, warm and cool conditions, thermoperiods, and increases (but no decreases) in daylength] were used in attempting to avert the second-instar diapause. All were unsuccessful. Thus, it was concluded that $P$. prasinus 
B-phenotype is univoltine and that its diapause in the second instar occurs independently of seasonal stimuli.

\section{Comparison between Nearctic and Palearctic species.}

\section{(1) Diapausing stage}

In our experiments with the three Nearctic species, the third instar was the life-stage that was most affected by short daylengths. Although daylength also significantly influenced developmental rates of the two other instars, especially the second instar, the effects were relatively small and usually restricted to LD 14:10. Therefore, it appears that the third instar may be the predominant, if not the only overwintering stage for the three Nearctic species. Nevertheless, we note that the laboratory results from $P$. picteti did not fully predict the overwintering stages that occurred in outdoor rearings (Canard et al., 1992). Thus, our above proposal regarding the overwintering stages of the Nearctic species awaits confirmation with field observations or rearings.

\section{(2) Photoperiodically sensitive stage(s)}

We reared the three Nearctic species under a range of constant daylengths from LD 16:8 to LD 10:14 for their entire life cycle. This procedure did not allow us to determine photoperiodically sensitive stages. Among the Palearctic species, the sensitive stages of only P. flavifrons, $P$. picteti, and $P$. clathratus have been studied (Principi et al., 1977; Canard et al., 1990; Principi \& Sgobba, 1993); in these three species, the second instar was the primary sensitive stage, but the first and early third instars were also involved. [Furthermore: it appears from results by Principi et al. (1977) that the photoperiodic experience of the parents and/or developing embryos (within eggs) also may influence diapause induction.]

\section{(3) Feeding during diapause}

Sometimes, larvae of the three North American species appeared to take food during the prediapause developmental delay, as well as during diapause. These observations concur with reports that $P$. flavifrons and $P$. picteti larvae may ingest prey and undergo significant weight gain during diapause (Principi et al., 1975; Canard et al., 1990). Usually, diapause in insects is associated with the cessation of feeding and growth (e.g., Tauber et al., 1986); thus the Pseudomallada species fall among the exceptions, and they provide opportunities to explore an intriguing facet of diapause.

\section{(4) Photoperiodic response - first instar}

The Nearctic and Western Palearctic species varied in whether or not photoperiod affected the developmental rates of the first instars. In $P$. macleodi and P. perfectus (Table 3), as well as in the Palearctic species P. picteti (Canard et al., 1990), short daylengths delayed first instar development slightly, but significantly. Interestingly, in $P$. sierra the situation was reversed; development was slightly, but significantly faster under short daylengths than under long daylength (LD 16:8). However, the biological relevance of this observation remains unexplained.
(5) Prediapause developmental delay - second instar

In both $P$. macleodi and $P$. sierra, LD 14:10 was the only photoperiod tested that reduced the rate of second instar development significantly (Table 3 ). This daylength is very near the critical photoperiod for diapause induction in the third instar (see \#6, below). In contrast, the results for $P$. perfectus were variable; in this species one or more short daylengths significantly slowed second instar development, but the geographic populations differed as to which photoperiods were effective. Regrettably, comparative data from daylengths very near the critical photoperiod are not available for most Palearctic species, and our results raise a number of questions. For example, the short daylength of LD 12:12 did not reduce the developmental rate of second instar P. clathratus from that observed at LD 16:8 (Principi \& Sgobba, 1987). However, we wonder whether this species' developmental rate would be reduced by an intermediate daylength which was slightly below the critical photoperiod (e.g., LD 14:10). In P. picteti, both the "intermediate" daylength of LD 12:12 and the "short" daylength of LD 8:16 delayed second instar development, with LD 12:12 being slightly more effective (Canard et al., 1990). Again, the developmental response to a slightly longer "intermediate" daylength (e.g., LD 14:10) is unknown.

$P$. prasinus B-phenotype presents the one notable exception to the pattern observed in most other Pseudomallada. This species was reported to overwinter in the second instar; moreover, in the laboratory, development stopped in second instars under all photoperiods tested, and an increase in daylength did not stimulate the resumption of development (Volkovich, 1998). It would be interesting to test whether a decrease in daylength (as would occur in nature) would stimulate molting and the subsequent induction of diapause in the third instar.

(6) Critical photoperiod for diapause induction - third instar

For all three Nearctic species, the critical photoperiod for diapause induction (at $\left.23.9^{\circ} \mathrm{C}\right)$ fell between LD 16:8 $(0 \%$ diapause) and LD 14:10 (100\% diapause). Comparable data over a range of photoperiods are unavailable except for one congeneric Palearctic species. In P. prasinus Aphenotype from the forest-steppe zone of Russia (Belgorod region, $\left.50^{\circ} \mathrm{N}, 36^{\circ} \mathrm{E}\right)$, the critical photoperiod fell between LD 16:8 and LD 18:6 (24 ${ }^{\circ}$ C) (Volkovich, 1998). Such a long critical photoperiod is not unexpected in a population from high latitudes.

\section{(7) Photoperiod and diapause depth}

In our study, the duration (depth) of diapause in all three species varied significantly when larvae were reared under a range of constant short-day photoperiods that fell below the critical photoperiod for diapause induction (Table 3). Previously, a similar type of variation was observed when the Palearctic species $P$. picteti (critical photoperiod between LD 12:12 and LD 16:8) was reared at constant LD 8:16 or LD 12:12 (Canard et al., 1990; Canard \& Grimal, 1993). The results from these species indicate that Pseudomallada larvae perceive and respond to the actual length 

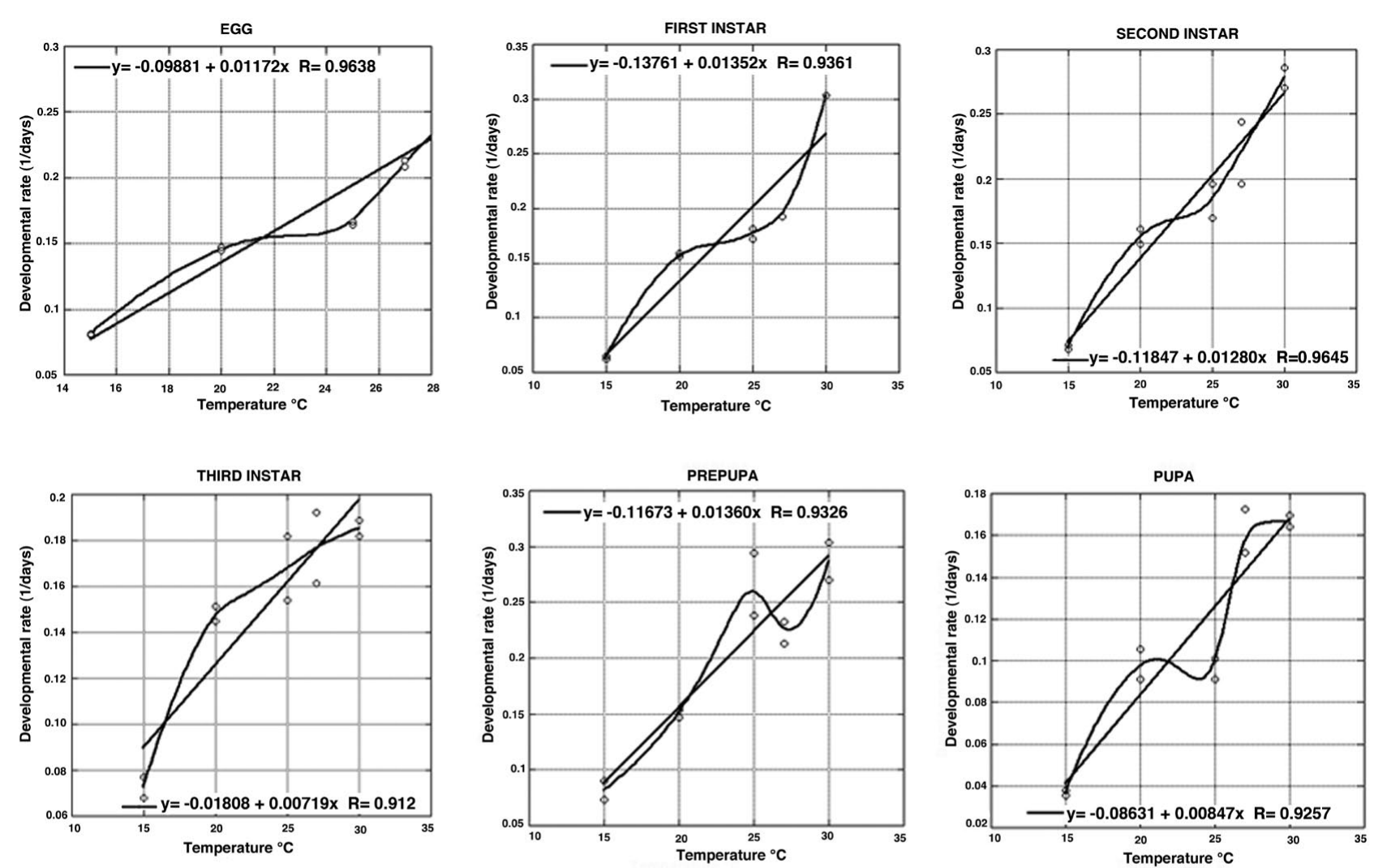

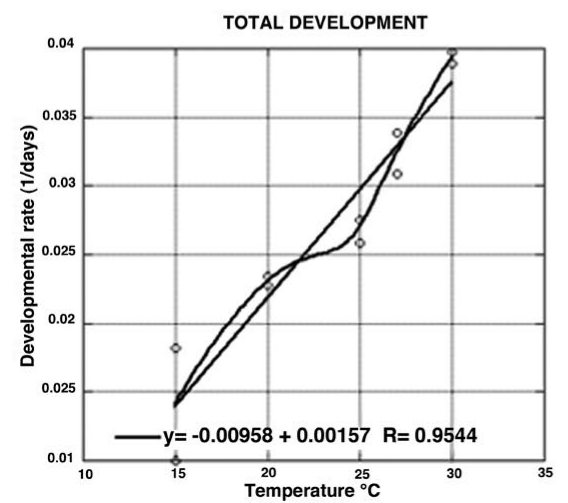

of the short days below the critical photoperiod. However, there was not a consistent or readily apparent pattern of variation, such as an inverse relationship between diapause depth and diapause-inducing daylengths, as in Chrysoperla carnea (Stephens) sensu lato (Tauber \& Tauber, 1973).

Additional results from two species $(P$. picteti and $P$. perfectus) indicate that at some periods in the life cycle, a decrease in daylength below the critical photoperiod may increase the depth of diapause. In P. picteti (with a critical photoperiod above LD 12:12), transfer of newly molted, prediapause second or third instars from LD 12:12 to LD $8: 16$ resulted in a more intense diapause than when larvae remained at either photoperiod without a change (i.e., constant LD 12:12 or LD 8:16) (Canard \& Grimal, 1993). When first instars experienced the same photoperiodic change, only a small proportion $(\sim 12 \%)$ delayed development.

In our test with young (10-day old), diapausing P. perfectus (Huachuca Mts, AZ), the transfer from a diapause-in-
Fig. 2. The relationship between temperature and the developmental rates for each life stage of Pseudomallada prasinus. The values for the plots were calculated from data on Table 1 in Pappas et al. (2008); each temperature had two data points - the average male and female developmental rates (see markers). To illustrate the patterns in the relationships, each set of data was fitted to a straight-line linear plot (regression equations given) and with a smoothed curve (KaleidaGraph, Version 4.5, Synergy Software).

ducing short daylength (LD 13:11) to an even shorter daylength (LD 10:14) induced a "deeper" (= longer) diapause than occurred at either of the constant short daylengths (Table 4B). Reciprocally, an increase in photoperiod (involving daylengths that remained below the critical photoperiod) reduced the depth of diapause and hastened its termination (Table 4B). In this test, the speed of response (time to cocoon formation) was quantitatively related to (i) the length of the final photoperiod - LD 10:14 (short-day control), LD 12:12 or LD 14:10) and (ii) the length of the time difference between the daylengths $-0,2$ or $4 \mathrm{~h}$.

Given the above results, we hypothesize that diapause depth in these Pseudomallada species is determined by a complex series of responses to photoperiodic stimuli, involving either or both (i) the measurement of actual daylengths and/or (ii) the perception of changes in daylength. These cues are detected during specific stages of development. Such complex response patterns are known to occur among other chrysopids that retain photoperiodic sensitiv- 
ity during the diapausing stage (e.g., in Chrysoperla spp.; see Tauber \& Tauber, 1970, 1973). However, the responses of Pseudomallada species appear to differ markedly from those of Chrysoperla, and they merit examination.

(8) Spontaneous and photoperiodic termination of diapause

In all Nearctic and Palearctic species tested (except for P. prasinus B-phenotype; see Volkovich, 1998), diapause often terminated "spontaneously" under constant conditions without the intervention of an apparent stimulus. The proportion of larvae that did so, varied considerably among species, populations, and treatments (see: Canard et al., 1992; also, Tables $3 \& 6$ here). In P. flavifrons and $P$. picteti, the photoperiodic and thermal conditions that the larvae experienced before and during diapause (especially during the second and early third instars) played an important role.

In all the species tested ( $P$. flavifrons, $P$. picteti, $P$. perfectus, $P$. sierra), transfer of diapausing larvae to a daylength longer than the critical photoperiod accelerated diapause development and hastened the initiation of spinning (Principi et al., 1977; Principi \& Sgobba, 1987; Canard et al., 1992, also, Tables $4 \& 5$ here). This response occurred whether the transfer took place early or late during diapause. Thus, diapausing larvae remain sensitive to daylength, and it would be useful to test whether an intense winter diapause (= "unachieving diapause" or "ately" of Canard \& Grimal, 1993) in the field would result in the heavy mortality that occurred under constant conditions in the laboratory. The naturally increasing and/or relatively long daylengths during late winter and spring would probably foreshorten a persistent diapause (Principi \& Sgobba, 1993).

\section{(9) Thermal effect on diapause termination}

A period of low temperature did not hasten (as it does in some diapausing insects) the rate of diapause development in the Nearctic P. perfectus, $P$. sierra, or the SP hybrids. On the contrary, a period of "chilling" during third instar diapause generally lengthened the total time for the larval period before cocoon formation. We suspect that in our experiments, chilling [which began relatively early (days 26 or 30) after the second to third instar molt] lengthened a photoperiodically sensitive period in the third instar, and thus induced a deeper diapause than that which occurred in the "unchilled" third instars. For comparison with P. flavifrons, see Principi et al. (1990).

(10) Photoperiodic responses of F1 P. perfectus $\times P$. sierra hybrids

Although there are no data from Paleactic species for comparison, we discuss our results from interspecific hybrids here, in part to stimulate analogous studies with phenotypes of $P$. prasinus. In our test (Table 6), the basic complement of diapause-inducing photoperiodic responses found in the parental genotypes is also expressed in the F1 interspecific hybrids (Table 6). Thus, $P$. perfectus and $P$. sierra seem to share a common genetic basis in their re- sponses to photoperiod. Also, it appears that $P$. sierra may be dominant to $P$. perfectus in the expression of the second instar's photoperiodically mediated, prediapause developmental delay. However, more tests are necessary to confirm this possibility. Furthermore, the significant difference between the hybrid genotypes and the parental genotypes in the duration of diapause in the third instar merits additional study.

It is worth noting that the species known as $P$. prasinus may contain a number of cryptic species (R.A. Pantaleoni, pers. commun.). For example, the two "phenotypes" that Volkovich (1998) studied (and considered as possible cryptic species) are difficult to distinguish morphologically, but they show a number of substantial biological differences including their phenologies. If these phenotypes could be hybridized in the laboratory, it would be of considerable interest to examine the inheritance of the diapause responses.

\section{(11) Temperature - development \& reproduction}

In our study of the thermal requirements for development and reproduction of $P$. perfectus (Kings Canyon population), there was substantial variation among developmental stages in the relationship between the rate of development and temperature. Graphs for the egg, prepupa-pupal period, total development, and preoviposition period (Figs 1A, 1E, $1 F)$ showed linear relationships that are typical of many insects (e.g., Honěk \& Kocourek, 1988). In contrast, growth rates of the larval stages (Figs 1B-1D) deviated considerably from linear; the deviation appeared most pronounced in the second instar.

Although such a non-linear relationship is not commonly reported, it also occurred in the Palearctic P. prasinus [see our graph (Fig. 2 here) of data previously published by Pappas et al., 2008]. In that species, second and third instars showed no significant variation in developmental times among several of the intermediate-range temperatures tested (Table 1 in Pappas et al., 2008), and their temperature-developmental rate relationships deviated greatly from linear for several stages (see our Fig. 2 here; also see Volkovich \& Blumental, 1997). In a later study, similar, but less pronounced, deviations from linearity occurred in P. prasinus fed a diet different from that in the earlier study (Pappas \& Koveos, 2011). In the second study, the authors recognized the deviation from linearity and utilized both linear and nonlinear tests in their statistical analyses and in their estimates of thermal requirements for development.

Based on the data from the above studies on P. perfectus and $P$. prasinus, as well as information concerning the relatively long critical photoperiods for diapause induction in both species (Table 3 here; Volkovich, 1998), we propose that the unusual thermal response curves reflect a photoperiodically based deceleration in prediapause and diapause development. For chrysopids, it has been shown that temperature conditions (constant and fluctuating) can have a strong positive or negative influence on diapause induction (e.g., Tauber et al., 1986); indeed, both P. flavifrons and $P$. prasinus express such an effect (Principi et al., 1990; Volkovich \& Blumental, 1997). Because our experiment, and the ones on P. prasinus, were conducted at LD 16:8, 
a photoperiod near the critical photoperiod, the various experimental temperatures may have shifted the critical photoperiod for diapause induction differentially; if so, the development of photoperiodically sensitive prediapause and diapausing stages would be expected to deviate from a linear relationship with temperature.

Pseudomallada - an attractive model system for photoperiodic studies

To date, experimental studies on the Palearctic and Nearctic species of Pseudomallada have demonstrated photoperiodic responses that elicit intriguing questions concerning the unexplored, underlying mechanisms. We propose that Pseudomallada could serve as a productive model system for further studies of insect photoperiodism. Our reasons are numerous: (i) The three larval instars have been demonstrated to have an extensive and malleable period of larval sensitivity and responsiveness to photoperiod. (ii) The larvae express a variety of the photoperiodic response pathways, some of which may be intricately intertwined with thermal responses. (iii) There is some evidence that time measurement in this group of insects is highly refined, but open to investigation; that is, larvae have relatively long developmental times during which they appear to measure actual daylengths and/or the direction or amount of daylength change. (iv) The genus contains large numbers of both Temperate Zone and Old World tropical species. Comparative study of these species could provide valuable insight into the evolution of diapause, photoperiodic responses, and related thermal adaptations in insects - topics that are very relevant to understanding the biological effects of climate change. (v) Some species will hybridize and produce viable offspring in the laboratory, thus opening possibilities for genetic investigation.

Together, the above suite of traits provides a wealth of opportunities for exploring the ecophysiology and evolution of photoperiodism, as well as the specific role of photoperiod, and the complex photoperiodic and thermal interactions, in timing insect seasonal development. An underlying (\& crucial) advantage for using this group in experimental research is that Pseudomallada species are among the predaceous insects that are amenable to rearing (see Pappas et al., 2008, 2011; Pantaleoni, 2014).

ACKNOWLEDGEMENTS. It is a pleasure to acknowledge the help and cooperation of the following individuals who either sent living, field-collected specimens to us or participated during our own collecting efforts in the field: R.B. Miller, J.A. Powell, J.R. Nechols, R.G. Helgesen, D.M. Helgesen, A.J. Tauber, M.J. Tauber, and P.J. Tauber. P.A. Adams (deceased) helped us identify the species studied here. We much appreciate B. Gollands' technical help with many of the experiments, and we thank J.J. Obrycki for thoughtful comments on the manuscript. The "Lacewing Digital Library" website, developed by J.D. Oswald (Texas A \& M University, College Station), was useful to this study. Finally, our work benefitted greatly from the support of the National Science Foundation (DEB-0542373 and earlier grants), NRI-USDA Competitive Grants Program (\#9802447 and earlier grants), Regional Project W-3185, and Cornell University.

\section{REFERENCES}

Adams P.A. 1978: A new species of Hypochrysa and a new subgenus and species of Mallada (Neuroptera: Chrysopidae). Pan-Pac. Entomol. 54: 292-296.

Adams P.A. \& Garland J.A. 1982: A review of the genus Mallada in the United States and Canada, with a new species (Neuroptera: Chrysopidae). — Psyche 89: 239-248.

Aspöck H., Hölzel H. \& Aspöck U. 2001: Kommentierter Katalog der Neuropterida (Insecta: Raphidioptera, Megaloptera, Neuroptera) der Westpaläarktis. — Denisia 2: 1-606.

BRooks S.J. 1997: An overview of the current status of Chrysopidae (Neuroptera) systematics. - Dt. Entomol. Z. (N.F.) 44: 267-275.

Brooks S.J. \& Barnard P.C. 1990: The green lacewings of the world: a generic review (Neuroptera: Chrysopidae). - Bull. Br. Mus. Nat. Hist. (Entomol.) 59: 117-286.

CAnARD M. \& Grimal A. 1993: Multiple action of photoperiod on diapause in the green lacewing Mallada picteti (McLachlan) (Neuroptera: Chrysopidae). - Boll. Ist. Entomol. "Guido Grandi" Univ. Bologna 47: 233-245.

Canard M., Grimal A. \& Hatté M. 1990: Larval diapause in the Mediterranean green lacewing Mallada picteti (MacLachlan) (Neuroptera: Chrysopidae): induction by photoperiod, sensitive and responsive stages. - Bol. Ist. Entomol. "Guido Grandi" Univ. Bologna 44: 65-74.

Canard M., Grimal A. \& Hatté M. 1992: How does the green lacewing Mallada picteti (McLachlan) overwinter? (Insecta: Neuroptera: Chrysopidae). In Canard M., Aspöck H. \& Mansell M.W. (eds): Current Research in Neuropterology. Proceedings of the Fourth International Symposium on Neuropterology (24-27 June 1991, Bagnères-de-Luchon, Haute-Garonne, France). Privately printed, Toulouse, pp. 87-93.

DaAne K.M. 2001: Ecological studies of released lacewings in crops. In McEwen P., New T.R. \& Whittington A.E. (eds): Lacewings in the Crop Environment. Cambridge University Press, Cambridge, pp. 408-423.

Dong K.-Z., Li W.-Z., Cui J.-Z. \& YANG X.-K. 2004: Three new species of Dichochrysa (Insecta: Neuroptera: Chrysopidae) from China, with a checklist of Chinese Dichochrysa. - Raffles Bull. Zool. 52: 67-74.

Haruyama N., Miyazaki Y., Nakahira K., Mochizuki A. \& NomuRA M. 2012: Developmental time and survival of trash-carrying versus naked green lacewings, with implications for their utility as augmentative biological control agents. - Ann. Entomol. Soc. Am. 105: 846-851.

Hölzel H. \& Duelli P. 1990: Remarks on the Chrysopidae of Madagascar (Insecta: Neuroptera). In Mansell M.W. \& Aspöck H. (eds): Advances in Neuropterology. Proceedings of the Third International Symposium on Neuropterology (3-4 February 1988, Berg en Dal, Kruger National Park, South Africa). South African Department of Agricultural Development, Pretoria, pp. 271-275.

Hölzel H., Оhм P. \& Stelzl M. 1994: Chrysopidae aus Senegal und Gambia II. Belonopterygini und Chrysopini (Neuroptera). - Entomofauna 15: 377-396.

Hölzel H., Онм P. \& Stelzl M. 1997: Chrysopidae von Namibia (Neuroptera, Chrysopinae). - Mitt. Münch. Entomol. Gesell. 87: 47-71.

HonĚK A. \& KocoureK F. 1988: Thermal requirements for development of aphidophagous Coccinellidae, Chrysopidae, Hemerobiidae, and Syrphidae - some general trends. - Oecologia 76: $455-460$. 
OswaLd J.D. 2013: Bibliography of the Neuropterida. Version 10.0 http://lacewing.tamu.edu/Bibliography/. Last accessed on 17 May 2014.

Pantaleoni R. 2014: Le Crisope. In Butturini A. \& Galassi T. (eds): Difesa fitosanitaria in produzione integrata. Calderini, Bologna, Milano, pp. 57-58.

Pappas M.L. \& Koveos D.S. 2011: Life-history traits of the predatory lacewing Dichochrysa prasina (Neuroptera: Chrysopidae): temperature-dependent effects when larvae feed on nymphs of Myzus persicae (Hemoptera: Aphididae). - Ann. Entomol. Soc. Am. 104: 43-49.

Pappas M.L., Broufas G.D. \& Koveos D.S. 2008: Effect of temperature on survival, development and reproduction of the predatory lacewing Dichochrysa prasina (Neuroptera: Chrysopidae) reared on Ephestia kuehniella eggs (Lepidoptera: Pyralidae). - Biol. Contr. 45: 396-403.

Pappas M.L., Broufas G.D. \& Koveos D.S. 2011: Chrysopid predators and their role in biological control. - J. Entomol. (Faisalabad) 8: 301-326.

PRINCIPI M.M. \& CASTELLARI P.L. 1970: Ibernamento e diapausa in alcune specie di crisopidi (Insecta, Neuroptera) viventi in Italia. - Atti Accad. Sci. Ist. Bologna Rc. (Cl. Sci. Fisiche 12) 7: 75-83.

Principi M.M. \& SgobBa D. 1985: La diapausa larvale in Anisochrysa flavifrons (Brauer) (Neuroptera, Chrysopidae). In: Atti XIV Congresso Nazionale Italiano di Entomologia (Palermo, Erice, Bagheria, 28 maggio - 1 giugno 1985). Vol. 1. Accademia Nazionale Italiana di Entomologia, Palermo, pp. 483490.

Principi M.M. \& SGobBa D. 1987: La diapausa larvale in Mallada (=Anisochrysa) flavifrons (Brauer) (Neuroptera Chrysopidae): cicli fotoperiodici responsabili dell'induzione, sviluppo di diapausa e attivazione, accrescimento ponderale dello stadio con diapausa. - Boll. Ist. Entomol. "Guido Grandi" Univ. Bologna 41: 209-231.

Principi M.M. \& SGobba D. 1993: La diapausa larvale in Mallada clathratus (Schneider) (Neuroptera Chrysopidae). - Boll. Ist. Entomol. "Guido Grandi”" Univ. Bologna 48: 75-91.

Principi M.M., Piazzi P. \& Pasqualin E. 1975: Influenza del fotoperiodo sul ciclo di sviluppo di Chrysopa flavifrons Brauer
(Neuroptera, Chrysopidae). - Boll. Ist. Entomol. Univ. Bologna 32: 305-322.

Principi M.M., Memmi M. \& Pasqualini E. 1977: Induzione e mantenimento della oligopausa larvale in Chrysopa flavifrons Brauer (Neuroptera, Chrysopidae). - Boll. Ist. Entomol. Univ. Bologna 33: 301-313.

Principr M.M., Memmi M. \& Sgobba D. 1990: Influenza della temperatura sulla diapausa larvale di Mallada flavifrons (Brauer) (Neuroptera, Chrysopidae). — Boll. Ist. Entomol. "Guido Grandi" Univ. Bologna 44: 37-55.

SÉMÉRIA Y. 1977: Discussion de la validité taxonomique du sousgenre Chrysoperla Steinmann. - Nouv. Rev. Entomol. 7: 235238.

Sмith R.C. 1922: The biology of the Chrysopidae. - Mem. Cornell Univ. Agric. Exp. St. 58: 1287-1372.

Tauber M.J. \& Tauber C.A. 1970: Photoperiodic induction and termination of diapause in an insect: response to changing daylengths. - Science 167: 170.

TAuber M.J. \& TAuber C.A. 1973: Quantitative response to daylength during diapause in insects. - Nature 244: 296-297.

Tauber M.J., Tauber C.A. \& Masaki S. 1986: Seasonal Adaptations of Insects (with foreword by A.D. Lees). Oxford Univ. Press, New York, 411 pp.

Tsukaguchi S. 1995: Chrysopidae of Japan (Insecta, Neuroptera). Privately printed, Osaka, $224 \mathrm{pp}$.

VolKovich T.A. 1998: Environmental control of seasonal cycles in green lacewings (Neuroptera, Chrysopidae) from the foreststeppe zone of Russia. In Panelius S.P. (ed.): Neuropterology 1997. Proceedings of the Sixth International Symposium on Neuropterology (13-16 July 1997, Helsinki, Finland). - Acta Zool. Fenn. 209: 263-275.

Volkovich T.A. \& Blumental A. 1997: Photo-thermoperiodic responses in some species of lacewings (Neuroptera: Chrysopidae): their role in diapause induction. - Eur. J. Entomol. 94: 435-444.

Withyсомве C.L. 1922: Notes on the biology of some British Neuroptera (Planipennia). - Trans. R. Entomol. Soc. Lond. 70: 501-594.

Received August 4, 2014; revised and accepted September 15, 2014 Prepublished online November 11, 2014 